\title{
Comparing near-infrared spectroscopy devices and their sensors for monitoring regional cerebral oxygen saturation in the neonate
}

\author{
Laura M.L. Dix ${ }^{1}$, Frank van Bel', Wim Baerts' and Petra M.A. Lemmers ${ }^{1}$
}

BACKGROUND: Near-infrared spectroscopy (NIRS) is an upcoming clinical method for monitoring regional cerebral oxygen saturation $\left(\mathrm{rSCO}_{2}\right)$ in neonates. There is a growing market offering different devices and sensors. Even though this technique is increasingly clinically applied, little is known about the similarities and/or differences in $\mathrm{rSCO}_{2}$ values between the different devices and sensors. The aim of this study was to compare the $\mathrm{rSCO}_{2}$ values obtained in (preterm) neonates with all available sensors of three frequently used NIRS devices.

METHODS: Fifty-five neonates admitted to our neonatal intensive care unit (NICU) were included in this study. $\mathrm{rSCO}_{2}$ was simultaneously monitored bilaterally with two different NIRS sensors (left and right frontoparietal) for at least $1 \mathrm{~h}$. Then, the sensors were switched, and measurements were collected for at least another hour.

RESULTS: We detected a rather close correlation between all investigated sensors from the three different NIRS devices, but absolute $\mathrm{rSCO}_{2}$ values showed substantial differences: BlandAltman analysis showed average differences from 10 to 15\%.

CONCLUSION: Although the $\mathrm{rSCO}_{2}$ values correlated well between different NIRS sensors, sometimes there were substantial differences between the absolute $\mathrm{rScO}_{2}$ values, which may complicate clinical application.

l:

nvestigating and monitoring the neonatal brain provides us with important clinical information. Besides continuous electroencephalogram monitoring, cranial ultrasound, magnetic resonance imaging, and magnetic resonance spectroscopy, near-infrared spectrometry (NIRS)-monitored regional cerebral oxygen saturation $\left(\mathrm{rScO}_{2}\right)$ is increasingly used (1-3). NIRS is a noninvasive, bedside technique which can be used to monitor mixed cerebral saturation, which correlates well with venous jugular bulb saturation (4-6) and estimates oxygen supply to the brain $(1,2)$. Normal values of $\mathrm{rScO}_{2}$ in the neonatal brain are reported to range from 55 to $85 \%(2,4-6)$.

NIRS-monitored $\mathrm{rSCO}_{2}$ cannot be used as a robust quantitative measure, given the large inter- and intrapatient variability (7). However, $\mathrm{rScO}_{2}$ provides us with absolute values, and movement artifacts have a minor influence, which facilitates its ease of use in clinical practice as a trend-monitoring device, analog to arterial saturation $\left(\mathrm{SaO}_{2}\right)$ monitoring (8-10). A study of Menke et al. (11) using the Critikon 2000 device (Critikon, Tampa, FL) showed that $\mathrm{rScO}_{2}$ could be determined with an acceptable reproducibility, whereas a study of Sorensen et al. (12) using the NIRO 300 device (Hamamatsu Photonics, Hamamatsu, Japan) showed a precision of cerebral saturation measurements (as represented by the tissue oxygenation index or TOI) of $\sim 5.2 \%$.

NIRS has shown its usefulness in multiple studies, it can function as an additional tool to detect a hemodynamically significant patent ductus arteriosus and the effects of (non) invasive ductal closure and as an important prognostic tool after severe perinatal asphyxia and (cardiac) surgery (13-16). When NIRS is combined with arterial blood pressure monitoring, the correlation between $\mathrm{rScO}_{2}$ and mean blood pressure can also be used to assess autoregulation of the cerebral arterial circulation (17).

To expand the use of NIRS in neonatal care, it is important that different NIRS devices provide similar results. Grubhofer et al. (18) compared the INVOS 3100 (Somanetics, Troy, MI) and NIRO 500 (Hamamatsu Photonics) devices during and after hypocapnia. Although the overall correlation between the two devices was significant, changes in cerebral hemoglobin oxygenation state were more accurately measured by the INVOS 3100. Cho et al. (19) studied the INVOS 3100 and NIRO 500. In addition, Yoshitani et al. (6) compared the INVOS 4100 (Somanetics) with the NIRO 300. Generally, the responses of the INVOS and NIRO devices to the cerebral oxygenation changes seem to be similar with a slightly stronger response by the NIRO device. Moreover, these devices show a positive correlation in response to a $\mathrm{CO}_{2}$ challenge test. However, Bland-Altman analysis revealed bias in the latter study in both absolute values and the percentage of changes. This indicates that measurements were not quite equivalent and varied depending on the chosen NIRS device and that different NIRS devices provide us with $\mathrm{rScO}_{2}$ values which correlate on average closely, but absolute $\mathrm{rScO}_{2}$ values may (although slightly) differ between different devices. 
In neonatal studies of NIRS-monitored $\mathrm{rScO}_{2}$, the NIRS sensors are, until now, the same as those used on adults. Because of the emerging use of NIRS-monitored $\mathrm{rScO}_{2}$ in the often sick and/or unstable (preterm) neonates, most NIRS-device suppliers are developing pediatric and neonatal sensors that are smaller and more suitable for the smaller heads. We earlier reported that pediatric and neonatal sensors provided us with substantially higher $\mathrm{rScO}_{2}$ values as compared with adult sensors, although they correlated well with each other (20). Differences in technical aspects such as different algorithms, near-infrared light emission source, number of wave lengths, or scattering subtraction may be underlying causes. However, for clinical purposes, it is important to define the normal range of $\mathrm{rScO}_{2}$ values in the (preterm) neonate. A prerequisite for this is that new devices and sensors provide similar results. Comparing the NIRS devices and sensors is therefore much needed and relevant.

The aim of this study was therefore to compare the $\mathrm{rScO}_{2}$ values obtained by different sensors of three frequently used NIRS devices in the neonatal setting.

\section{RESULTS}

Clinical characteristics of all the included infants are shown in Table 1. During the actual data collection, all infants were hemodynamically stable, had normal blood gasses, and were not disturbed by feeding or changing. $\mathrm{rScO}_{2}$ signals were measured in 67 neonates bilaterally. Of these, 55 provided reliable and representative $\mathrm{rScO}_{2}$ signals. Figure 1 shows the simple regression plots of NIRS-monitored $\mathrm{rScO}_{2}$ as a function of comparing two different devices. Figure 2 shows the BlandAltman plots with the limits of agreement between the two $\mathrm{rScO}_{2}$ signals analyzed per measuring value. Statistical analysis was performed and described per infant. An example is shown in Figure 3. Detailed results are given in the following sections.
Sixteen neonates were monitored with the adult sensor and the neonatal sensor of the INVOS 5100C (Covidien, Troy, MI). Of these, 13 resulted in two measuring periods of $1 \mathrm{~h}$ each and 3 in only one measuring period of $1 \mathrm{~h}$. Mean $\mathrm{rScO}_{2}$ was $76 \pm 7 \%$ for the neonatal sensor, and $66 \pm 10 \%$ for the adult sensor. These means differ significantly $(P<0.001)$. There appeared a close correlation between the two sensors $(r=0.88, P<0.001)$ (Figure 1a). Bland-Altman analysis revealed an average difference of $10 \pm 5 \%$. The corresponding limits of agreements are 0-20\% (Figure 2a, represented as per measuring value).

In comparing the pediatric sensor with the adult sensor, both from the INVOS 5100C (Covidien), 14 infants were NIRS measured. One infant resulted in only one measuring period of $1 \mathrm{~h}$. Mean $\mathrm{rScO}_{2}$ was $80 \pm 10 \%$ for the pediatric sensor, and $70 \pm 11 \%$ for the adult sensor $(P<0.001)$. Linear regression showed a correlation coefficient of $r=0.89, P<0.001$ (Figure 1b). The Bland-Altman plot shows an average difference of $10 \pm 5 \%$. Limits of agreement are $0-20 \%$ (Figure 2b, represented as per measuring value). The neonatal sensor of the Fore-Sight device (CAS Medical Systems, Branford, CT) was compared with the adult sensor of the INVOS 5100C (Covidien) in 14 infants. In three infants, measurements resulted in only one measuring period of $1 \mathrm{~h}$. Mean $\mathrm{rScO}_{2}$ was $81 \pm 5 \%$ for the ForeSight neonatal sensor and $66 \pm 8 \%$ for the INVOS (Covidien) adult sensor $(P<0.001)$. The linear regression coefficient was $r=0.74(P=0.002)$ (Figure 1c). The average difference was $16 \pm 6 \%$ and limits of agreement were $4-27 \%$ (Figure 2c; represented as per measuring value).

The last comparison was between the Equanox (NONIN Medical, Plymouth, MN) sensor and the Fore-Sight neonatal sensor. Eleven neonates were measured, of whom three resulted in one measuring period of $1 \mathrm{~h}$ and eight in two measuring periods. Mean $\mathrm{rScO}_{2}$ values were $78 \pm 6 \%$ for the Fore-Sight neonatal sensor and $65 \pm 5 \%$ for the Equanox sensor

Table 1. Patient characteristics

\begin{tabular}{|c|c|c|c|c|}
\hline Sensors & $\begin{array}{c}\text { INVOS neonatala }- \text { INVOS } \\
\text { adult }^{\mathrm{a}}\end{array}$ & $\begin{array}{c}\text { INVOS pediatric }{ }^{\mathrm{a}}-\text { INVOS } \\
\text { adult }^{\mathrm{a}}\end{array}$ & $\begin{array}{c}\text { Fore-Sight neonatal }{ }^{\mathrm{b}}- \\
\text { INVOS adult }^{\mathrm{a}}\end{array}$ & $\begin{array}{l}\text { Fore-Sight neonatal }^{\text {b }} \text { - } \\
\text { Equanox adult }^{c}\end{array}$ \\
\hline Total $N$ & 16 & 14 & 14 & 11 \\
\hline Male/female & $5 / 11$ & $5 / 9$ & $5 / 9$ & $6 / 5$ \\
\hline $\mathrm{BW}(\mathrm{g}) ;$ mean $\pm \mathrm{SD}$ & $1,330 \pm 790$ & $2,104 \pm 1106$ & $1,214 \pm 317$ & $1,683 \pm 983$ \\
\hline $\mathrm{GA}(w \mathrm{k}) ;$ mean $\pm \mathrm{SD}$ & $30 \pm 3$ & $33 \pm 5$ & $29 \pm 2$ & $31 \pm 4$ \\
\hline APGAR 5 min; median (range) & $7(1-10)$ & $9(7-10)$ & $8(3-10)$ & $9(3-10)$ \\
\hline Postnatal age (d); median (range) & $2(1-16)$ & $3(0-31)$ & $2(1-15)$ & $4(0-19)$ \\
\hline \multicolumn{5}{|l|}{ Respiratory support } \\
\hline None & 1 & 5 & 1 & 3 \\
\hline NF & 1 & 3 & 3 & 4 \\
\hline CPAP & 8 & 2 & 5 & 2 \\
\hline SIMV & 6 & 4 & 5 & 2 \\
\hline \multicolumn{5}{|l|}{$\mathrm{SGA}(<\mathrm{p} 10)$} \\
\hline Yes/no & $0 / 16$ & $0 / 14$ & $0 / 14$ & $1 / 10$ \\
\hline
\end{tabular}

BW, birth weight; CPAP, continous positive airway pressure; GA, gestational age; NF, nasal flow $0.5 \mathrm{I} / \mathrm{min}$; SGA, small for gestational age; SIMV, synchronized intermittent mandatory ventilation.

aINVOS $5100 C$ (Covidien). ${ }^{b}$ Fore-Sight (CAS Medical Systems). ‘ Equanox model 7600 (NONIN Medical). 

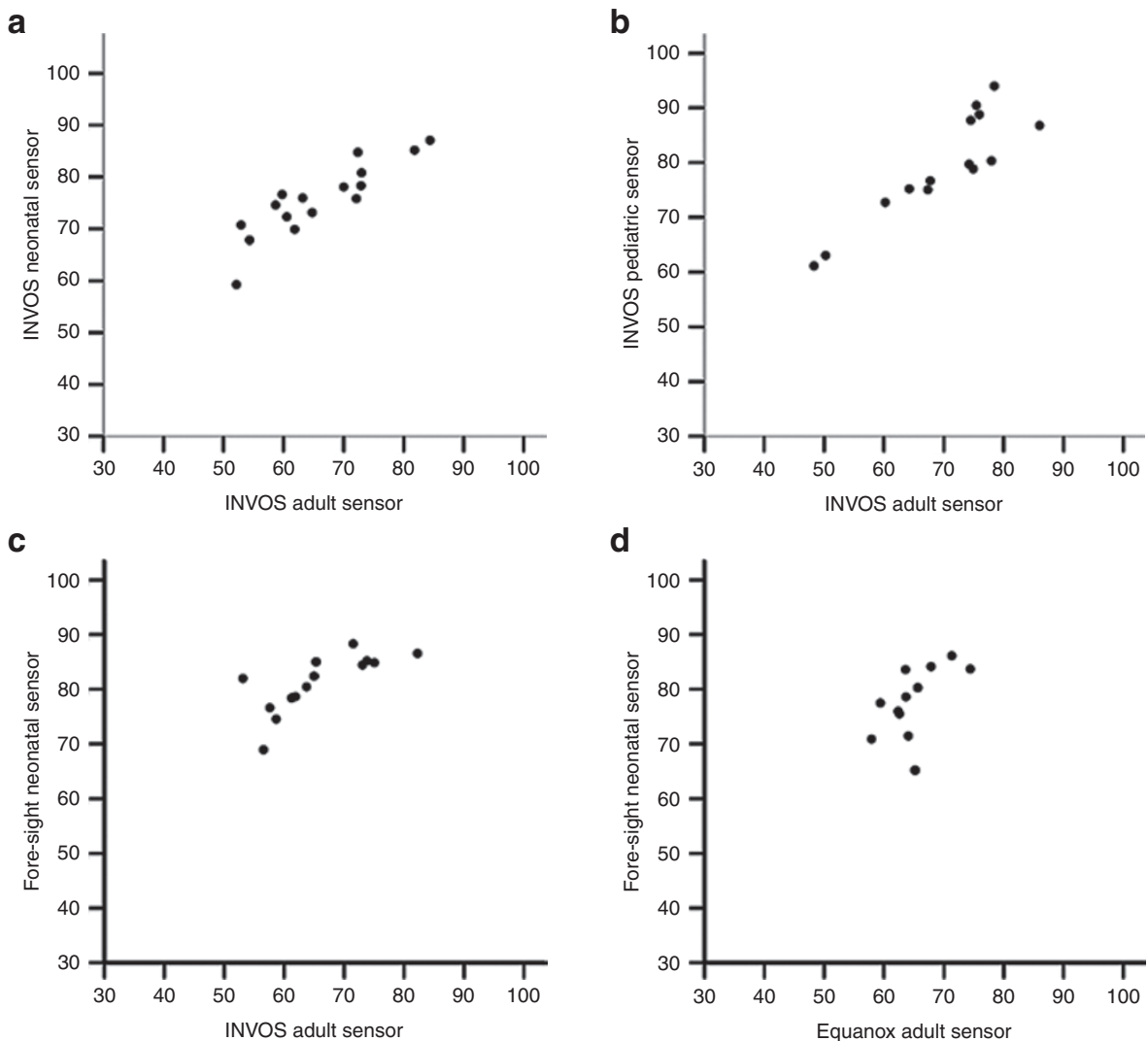

Figure 1. Simple regression plots of the near-infrared monitored regional cerebral oxygen saturation $\left(\mathrm{rScO}_{2}\right)$ combinations. (a) INVOS adult sensor (SomaSensor SAFB-SM) vs. INVOS neonatal sensor (Oxyalert CNN) (both by Covidien) $(r=0.88 ; P<0.001)$. (b) INVOS adult sensor (SomaSensor SAFB-SM) vs. INVOS pediatric sensor (SomaSensor SPFB) (both by Covidien) $(r=0.98 ; P<0.001)$. (c) INVOS adult sensor (SomaSensor SAFB-SM) (Covidien) vs. ForeSight neonatal sensor (small sensor) (CAS Medical Systems) $(r=0.74 ; P=0.002)$. (d) Equanox sensor (Classic Sensor 8000CA) (NONIN Medical) vs. ForeSight neonatal sensor (small sensor) (CAS Medical Systems) $(r=0.57 ; P=0.054)$.

$(P<0.001)$. Linear regression coefficient $(r)$ was $0.62(P=0.054)$ showing a similar pattern of differences with the Fore-Sight and INVOS (Covidien) comparisons (Figure 1d). The average difference between the Equanox and Fore-Sight sensors was $15 \pm 4 \%$ with limits of agreement of $7-23 \%$ (Figure 2d; represented as per measuring value). The linear regression analysis and Bland-Altman analysis are summarized in Tables 2 and 3 , respectively.

\section{DISCUSSION}

This study shows a substantial difference in $\mathrm{rScO}_{2}$ between the adult NIRS sensors, irrespective of the brand of the NIRS device on the one hand and the pediatric and neonatal sensors of the two devices on the other hand. The pediatric and neonatal sensors measure consequently higher $\mathrm{rScO}_{2}$ values, ranging from 10 to $14 \%$. The $\mathrm{rScO}_{2}$ values determined with the adult sensors from the INVOS 5100C (Covidien) and the Equanox 7600 devices were comparable although no direct comparison was possible here because of interference of the NIRS signals. Moreover, the $\mathrm{rScO}_{2}$ values obtained with the two neonatal sensors and the pediatric sensor from INVOS (Covidien) provided us with comparable results.

These results are important for clinical practice because the clinician must be able to rely on NIRS-determined cerebral oxygenation using $\mathrm{rScO}_{2}$. The clinical application of NIRS is especially important in detecting hypoxia for preventing hypoxic damage in the neonatal brain. Earlier experimental and human studies in neonatal animals (1- to 3-day-old piglets) and term neonates, respectively, almost always performed with the older (adult) sensors showed that $\mathrm{rScO}_{2}$ values $<35-44 \%$ for at least $30-60 \mathrm{~min}$ lead to functional and/ or anatomical hypoxic brain damage (21-23). The new information gathered in this study strongly suggest that the lower limit of acceptable $\mathrm{rScO}_{2}$ values obtained with the neonatal sensors, irrespective which NIRS device has been used, will be higher. Likewise, the upper limit of $\mathrm{rScO}_{2}$ values to avoid hyperoxia will be different when using the neonatal sensors of the NIRS devices investigated. Important to state here is that this issue has not yet been well investigated at all. In our neonatal intensive care unit (NICU) where we routinely monitor all preterm neonates below 30 weeks of gestation for the first 3 days of life during the last 5 years with the small adult sensor of the INVOS 5100C (Covidien), we use an upper limit 85\% being two standard deviations above the expected mean value $\pm 1 \mathrm{SD}(71 \pm 7 \%)$. We obtained these data from a population of $\sim 500$ babies (unpublished data), which is well in line with normative data of another study in preterm infants investigated with NIRS devices using adult sensors $(8,12)$. Hyperoxia has 
a

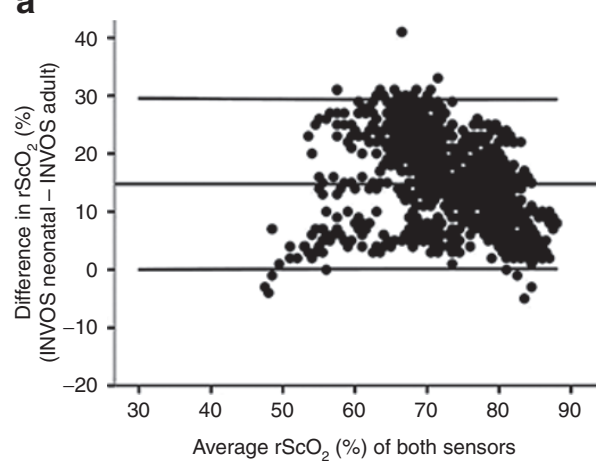

C

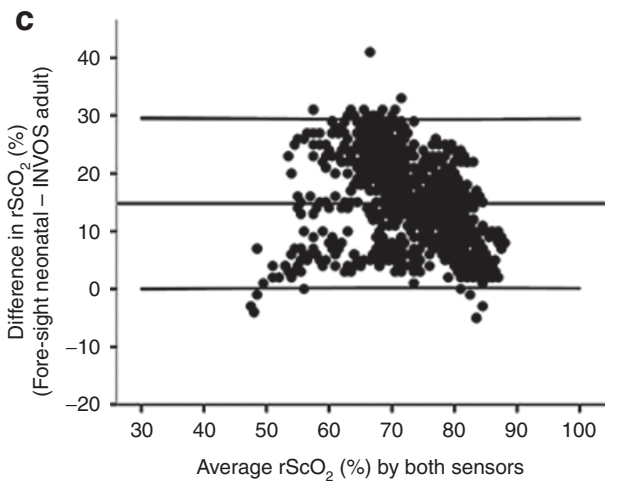

b

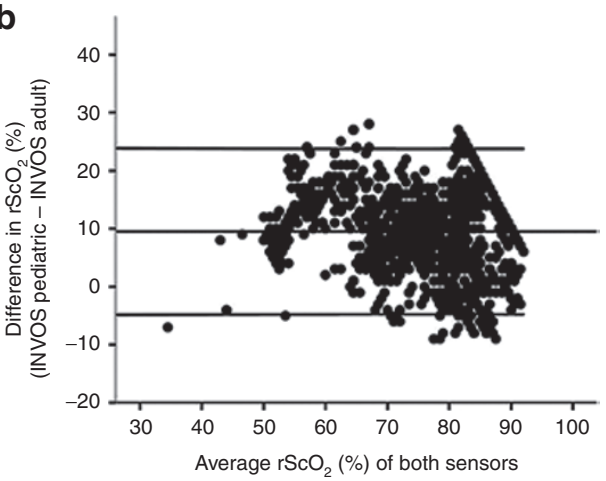

d

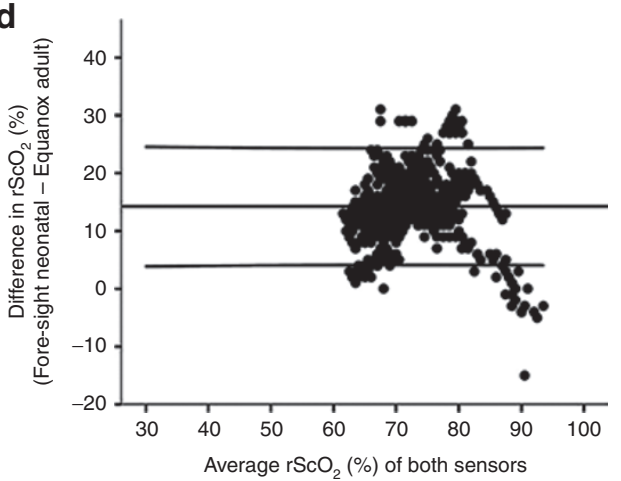

Figure 2. Bland-Altman plots of the near-infrared spectroscopy (NIRS) monitored regional cerebral oxygen saturation $\left(\mathrm{rScO}_{2}\right) \mathrm{combinations}(\mathrm{depicted}$ as per-measuring values). The black lines represent the lower and upper limits of agreement and the average difference. (a) INVOS adult sensor (SomaSensor SAFB-SM) and INVOS neonatal sensor (Oxyalert CNN) (both by Covidien), average difference, $10 \pm 7 \%$; limits of agreement, -4 to $24 \%$. (b) INVOS adult sensor (SomaSensor SAFB-SM) vs. INVOS pediatric sensor (SomaSensor SPFB) (both by Covidien), average difference, $10 \pm 7 \%$; limits of agreement, -5 to $24 \%$. The straight line on the right side of panel $\mathbf{b}$ indicates the upper limit of the INVOS (Covidien) device. As values become higher, the difference between the two sensors cannot increase along because of the upper limit of $95 \%$ installed by the manufacturer. (c) INVOS adult sensor (SomaSensor SAFB-SM) (Covidien) and Fore-Sight neonatal sensor (small sensor) (CAS Medical Systems), average difference, 15 \pm 7\%; limits of agreement, 0-30\%. (d) Equanox sensor (Classic Sensor 8000CA) (NONIN Medical Inc) and Fore-Sight neonatal sensor (small sensor) (CAS Medical Systems Inc), average difference, $14 \pm 5 \%$; limits of agreement, $4-25 \%$.

been suspected to be toxic and to negatively influence longterm cognitive and motor outcome of especially the extremely preterm neonates born before $28 \mathrm{wk}$ of gestation (24). A complicating factor here is that the neonatal sensors of INVOS (Covidien) and Fore-Sight do not measure $\mathrm{rScO}_{2}$ values above $90 \%$ as measured with the adult sensors: as can be seen in Figures $2 \mathrm{a}-\mathbf{d}$, the values of the pediatric and neonatal sensors of INVOS (Covidien) cannot exceed 95\% (upper limit installed by manufacturer) when the adult sensors are still within range of $85-95 \%$. This makes it impossible to rely on these measurements in case of assumed hyperoxia and greatly impair the use of neonatal and pediatric sensors in NIRS-monitored $\mathrm{rScO}_{2}$ in clinical practice. We, therefore, continue using the original adult sensors in our extremely preterm babies, where we have a lot of experience with and an abundant amount of data, until the reason(s) for the discrepancy between adult and pediatric/ neonatal sensors with respect to $\mathrm{rScO}_{2}$ values has been solved.

We can only speculate about the reason for the discrepancy in $\mathrm{rSCO}_{2}$ values between the different types of NIRS sensors. As we already stated in an earlier report, we postulated that the differences between adult and neonatal sensors are related to differences in the processing of the received NIRS signal. According to the manufacturer of the INVOS 5100C (Covidien) device, for instance, the neonatal sensor has been engineered to have a higher sensitivity. The algorithm for this neonatal sensor has indeed been adjusted to increased signal intensities transmitted through the thinner infant's skull (20). This makes it easier for the ambient light to enter, and may account for the $10-14 \%$ higher values of $\mathrm{rCO}_{2}$ we found in this study, although it may be expected that the instrument will adjust for different light intensities. It is furthermore important to realize that the NIRS devices present in this study use different measurement techniques of $\mathrm{rScO}_{2}$, spatially resolved spectroscopy, and the principles of the Beer-Lambert law to measure cerebral oxygen saturation. Although interference between the two sensors (left and right frontoparietal positions) may account for the higher $\mathrm{rScO}_{2}$ values, this does not seem very likely because the preamplifier and the distance between the NIRS sensors actually prevent this interference. Other differences in technical details, low hemoglobin values (not the case in our investigated group, data not shown), or extra cranial blood flow could contribute to the differences between sensors but are not very probable. Differences in intracranial blood flow could account for differences between the two sides of the neonatal head. We tried to compensate for differences between left and right positions by measuring both the sides with the two sensors. Earlier studies 
have shown that differences are usually within the range of $7 \%$; recent work compared the neonatal sensor and found even higher differences between left and right positions (20). Finally, as the sensors are of different sizes and use different wavelengths, the size of the measured area and signal depth could be uneven. Although beyond the scope of this study, other reasons for differences between $\mathrm{rScO}_{2}$ values measured

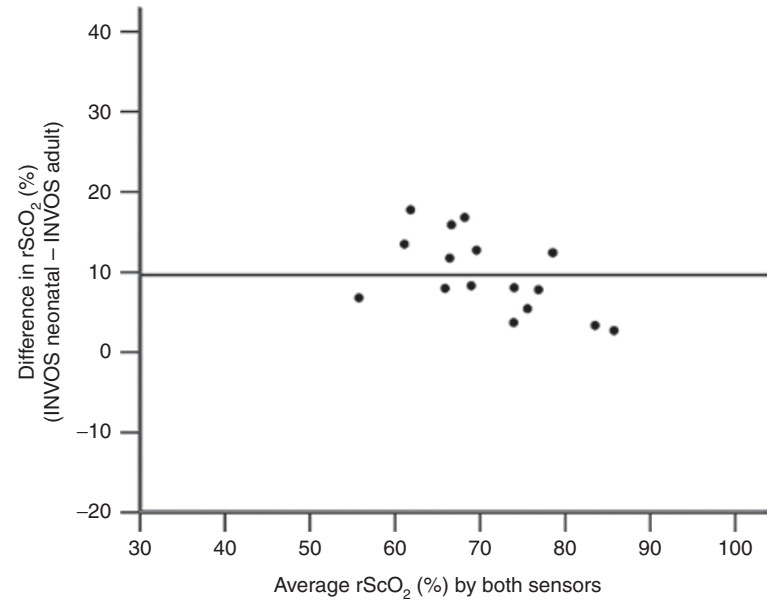

Figure 3. Bland-Altman plot of the near-infrared spectroscopy (NIRS) monitored regional cerebral oxygenation $\left(\mathrm{rSCO}_{2}\right)$ analyzed per infant. The black line in the figure represents the average difference of the $\mathrm{rCO}_{2}$ monitored with the INVOS adult sensor (SomaSensor SAFB-SM) and INVOS neonatal sensor (Oxyalert CNN) (both by Covidien). Average difference, $10 \pm 5$; limits of agreement, $0-20 \%$.

Table 2. Linear regression analysis

\begin{tabular}{|c|c|c|c|c|c|}
\hline Sensors & $\begin{array}{l}\text { INVOS } \\
\text { adult }^{\text {a }}\end{array}$ & $\begin{array}{c}\text { INVOS } \\
\text { neonatal }^{\mathrm{a}}\end{array}$ & $\begin{array}{c}\text { INVOS } \\
\text { pediatric }^{\mathrm{a}}\end{array}$ & $\begin{array}{l}\text { Fore-Sight } \\
\text { neonatal }^{b}\end{array}$ & $\begin{array}{c}\text { Equanox } \\
\text { adult }^{c}\end{array}$ \\
\hline$N$ & & 16 & 14 & 14 & 11 \\
\hline \multirow{2}{*}{$\begin{array}{l}\mathrm{rScO}_{2}(\%) \\
\text { mean } \pm \mathrm{SD}\end{array}$} & \multirow[t]{2}{*}{$66 \pm 10$} & $76 \pm 7$ & & & \\
\hline & & $P<0.001$ & & & \\
\hline
\end{tabular}

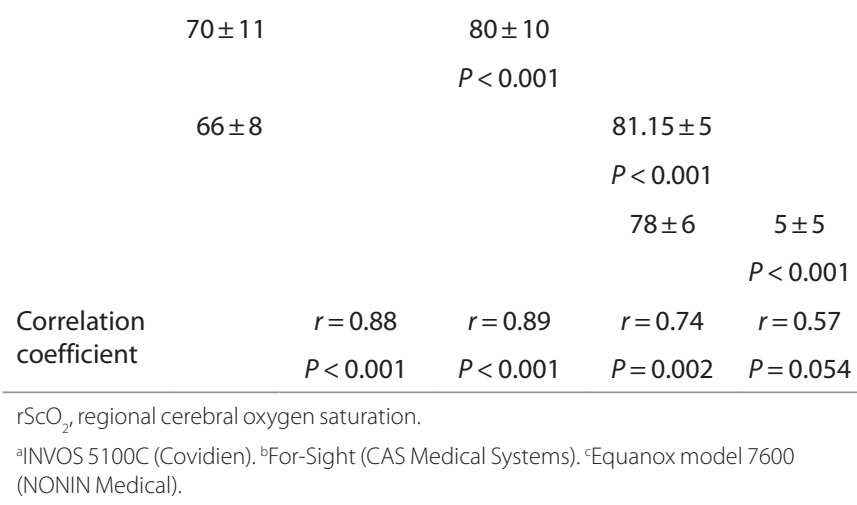

in extremely preterm infants can be manifold. Besides differences in the techniques as stated above, differences in postmenstrual and postnatal age (25-28) or differences induced by the different locations of the brain under investigation (29) may contribute to differences in $\mathrm{rScO}_{2}$. It will be worthwhile and clinically very important to further investigate these issues in relation to cerebral oxygen saturation.

The main disadvantage of the adult sensors as compared with the smaller pediatric or neonatal sensors is its size. Intensive neonatal care is often extensive including the need for repeated cranial ultrasound investigations, monitoring of the electrical brain activity with amplitude-integrated electroencephalogram, and the need for artificial ventilation. Considering how small a neonatal head can be in these extremely preterm babies, smaller NIRS sensors could surely be of advantage; but only when their technical details are fully known and reliable, $\mathrm{rScO}_{2}$ values can be measured.

Further research should therefore focus on whether it is possible to correct for the differences between the different types and brands of commercially available sensors. This issue is particularly pressing, given the fact that recent (although preliminary) research suggests that $\mathrm{rScO}_{2}$ values are indeed higher in the (preterm) neonate and were reported to be between 79 and $85 \%$ (30).

In summary, we conclude that there appears to be a good correlation between the different NIRS sensors used in the NICU. However, differences between $\mathrm{rScO}_{2}$ values measured with the adult sensor and the pediatric and neonatal sensors range between 10 and 14\%, being higher in the pediatric and neonatal sensors.

\section{METHODS}

Sixty-seven neonates without severe illness or respiratory failure admitted to the NICU of the Wilhelmina Children's Hospital in Utrecht, The Netherlands, were measured bilaterally (left and right frontoparietal) NIRS-determined $\mathrm{rScO}_{2}$. Fifty-five infants provided us with representative measurements. The average gestational age was $30.7 \pm 3.9$ weeks and birth weight $1,562 \pm 886 \mathrm{~g}$. Measurements were considered as nonrepresentative when differences exceeded $30 \%$, when abundant artifacts were present, or when a stable monitoring period of $1 \mathrm{~h}$ could not be accomplished.

Informed consent was obtained, and the study was approved by the Institutional Review Board of the Wilhelmina Children's Hospital in Utrecht.

Obstetric and intrapartum data were collected from the hospital records. Neonatal data were collected prospectively. The attending neonatologist made all clinically important decisions.

NIRS-determined $\mathrm{rScO}_{2}$ was used as an estimator for changes in cerebral oxygenation. When an infant was treated with phototherapy, an extra covering sheet was placed over the sensor to prevent the therapeutic light from affecting the $\mathrm{rScO}_{2}$ measurements. Three frequently

Table 3. Bland-Altman analysis

\begin{tabular}{|c|c|c|c|c|}
\hline Sensors & $\begin{array}{l}\text { INVOS neonatala }^{a}-\text { INVOS }_{\text {adult }^{\mathrm{a}}} \\
\end{array}$ & $\begin{array}{l}\text { INVOS pediatric }{ }^{\mathrm{a}}-\text { INVOS }^{\text {adult }} \\
\text { adu }^{\mathrm{a}}\end{array}$ & $\begin{array}{l}\text { Fore-Sight neonatal } \\
\text { adult }^{\mathrm{b}} \text {-INVOS }\end{array}$ & $\begin{array}{l}\text { Fore-Sight neonatal }^{\text {b }}- \\
\quad \text { Equanoxadult }\end{array}$ \\
\hline$N$ & 16 & 14 & 14 & 11 \\
\hline Limits of agreement (\%) & $0-20$ & $0-20$ & $4-27$ & $7-23$ \\
\hline
\end{tabular}

alNVOS $5100 C$ (Covidien). ${ }^{b}$ Fore-Sight (CAS Medical Systems). CEquanox model 7600 (NONIN Medical). 
Table 4. NIRS devices and sensors

\begin{tabular}{ll}
\hline NIRS devices & \multicolumn{1}{c}{ Sensors } \\
\hline INVOS oximeter $^{\mathrm{a}}$ & Small adult SomaSensor (SAFB-SM) (standard) \\
& $\begin{array}{l}\text { Pediatric SomaSensor (SPFB) } \\
\text { OxyAlert Neonatal Sensor (CNN) }\end{array}$ \\
& Neonatal Sensor (small sensor) \\
Fore-Sight oximeter & \\
Equanox model $7600^{\mathrm{c}}$ & Adult sensor (Classic Sensor 8000 CA)
\end{tabular}

NIRS, near-infrared spectroscopy.

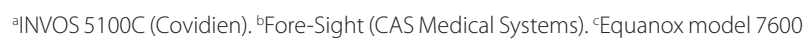
(NONIN Medical).

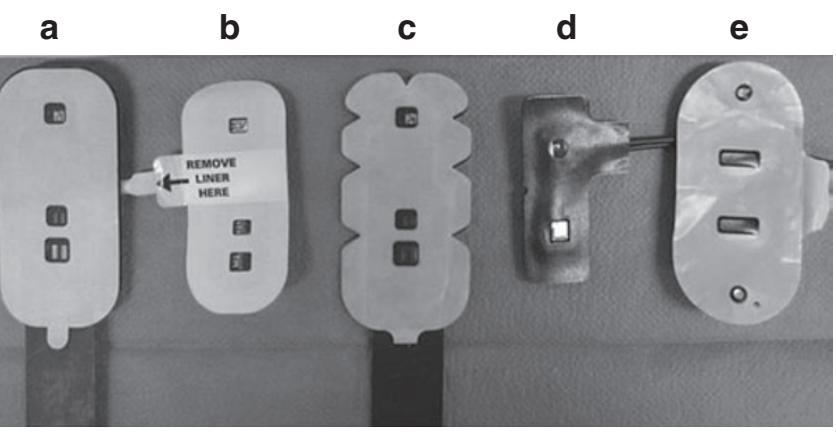

Figure 4. The different NIRS sensors used for comparison. (a) INVOS adult sensor (SomaSensor SAFB-SM) (Covidien). (b) INVOS neonatal sensor (Oxyalert CNN) (Covidien). (c) INVOS pediatric sensor (SomaSensor SPFB) (Covidien). (d) Fore-Sight neonatal sensor (small sensor) (CAS Medical Systems). (e) Equanox sensor (Classic Sensor 8000CA) (NONIN Medical).

used NIRS devices in the NICU-the INVOS 5100C (Covidien), the Equanox model 7600, and the Fore-Sight systems-were compared.

The INVOS 5100C (Covidien) sensors use light-emitting diodes to emit near-infrared light of two wavelengths $(730$ and $810 \mathrm{~nm})$. The nature and quantity of the recaptured near-infrared light reflects the amount of $\mathrm{HHb}$ and $\mathrm{O}_{2} \mathrm{Hb}$, used to calculate $\mathrm{rScO}_{2}$. Two detectors are located next to the light-emitting diodes. By subtracting the shallow (shorter) signal from the deeper (further) signal, surface interference contamination is minimized $(31,32)$. Clinical applicability of the INVOS device in neonates has been researched (33). The INVOS 5100C (Covidien) can be used with three different sensors: the adult (SomaSensor SAFB-SM), pediatric (SomaSensor SPFB), and neonatal sensor (Oxyalert CNN). As the adult sensor has been exclusively used at the Wilhelmina Children's Hospital in the clinical setting, this sensor serves as reference measurement.

The Equanox model 7600 uses two light-emitting diodes (Classic Sensor 8000CA), sending out a near-infrared signal composed of three wavelengths $(730,810$, and $880 \mathrm{~nm})$. The two light-emitting diodes are in the middle of the sensor, flanked by two photo diodes to capture the reflected light. Double detectors reduce intervening tissue and surface effects. At the time of the study, no neonatal sensor for the Equanox device was available. The Equanox device has thus far only one (adult) sensor.

The Fore-Sight tissue oximeter and its neonatal sensor (small sensor) use four different wavelengths in the near-infrared light spectrum (from 670-780-805-850 $\mathrm{nm}$ ). One light emitting source is placed next to an absorbing diode. An overview of the different devices and their sensors is shown in Table 4.

\section{Study Design}

Five different NIRS sensors from the three NIRS devices were compared (Figure 4). Two sensors at the time were applied to the frontoparietal part of the head of the neonate, one on each side symmetrically. Sensors were fixated with an opaque elastic bandage to shield the optodes from ambient light. After a period of at least $1 \mathrm{~h}$, sensors were switched to the contralateral side to collect two periods of $60 \mathrm{~min}$ of a stable clinical episode, without interference due to, for example, feeding or care. The INVOS (Covidien) adult sensor was used as reference measurement. However, in the course of this research, a practical limitation occurred in comparing the Equanox sensor to the INVOS (Covidien) adult sensor. Strong interference between the two sensors resulted in unreliable results. We therefore adjusted the study design and compared the Equanox sensor with the Fore-Sight neonatal sensor, where the interference problem did not occur. The resulting combinations were as follows:

- INVOS (Covidien) adult sensor (SomaSensor SAFB-SM) vs. INVOS (Covidien) neonatal sensor (Oxyalert CNN)

- INVOS (Covidien) adult sensor (SomaSensor SAFB-SM) vs. INVOS (Covidien) Somanetics pediatric sensor (SomaSensor SPFB)

- INVOS (Covidien) adult sensor ((SomaSensor SAFB-SM) vs. Fore-Sight neonatal sensor (small sensor)

- Equanox sensor (Classic Sensor 8000CA) vs. Fore-Sight neonatal sensor (small sensor)

To correct for the $7 \%$ difference between left and right positions, we measured both the devices bilaterally resulting in two measuring periods (34). Of the 55 included neonates, 10 resulted in only one monitoring period of an hour. In our experience, it usually takes $5 \mathrm{~min}$ to produce a reliable signal after application. We therefore did not include the first $5 \mathrm{~min}$ into the analysis of the results. Signal Base (a program especially designed at the Wilhelmina Children's Hospital for NIRS signal analysis) was used to convert and to analyze the obtained $\mathrm{rScO}_{2}$ signals.

\section{Statistical Analysis}

Data were summarized as mean values \pm SD or as median values and ranges where appropriate. Simple linear regression analysis was used to analyze the correlation between the different obtained $\mathrm{rScO}_{2}$ signals. Bland-Altman statistics compares the difference between the signals with the average $\mathrm{rScO}_{2}(35)$. Representative $\mathrm{rScO}_{2}$ signals were converted in median values with a sampling rate of one value per minute, because the different NIRS devices use different sampling rates and to exclude the influence of ' 0 '-values (artifacts). Sixty successive values of each sensor (and if representative of both sides) were analyzed with the Signal Base program. No signals were removed or given less weight during the calculations. We used SPSS 17.0 (SPSS, Chicago, IL) for statistical analysis.

\section{REFERENCES}

1. Wolf M, Greisen G. Advances in near-infrared spectroscopy to study the brain of the preterm and term neonate. Clin Perinatol 2009;36:807-34, vi.

2. van Bel F, Lemmers P, Naulaers G. Monitoring neonatal regional cerebral oxygen saturation in clinical practice: value and pitfalls. Neonatology 2008;94:237-44.

3. Naulaers G, Meyns B, Miserez M, et al. Use of tissue oxygenation index and fractional tissue oxygen extraction as non-invasive parameters for cerebral oxygenation. A validation study in piglets. Neonatology 2007;92:120-6.

4. Nagdyman N, Fleck T, Schubert S, et al. Comparison between cerebral tissue oxygenation index measured by near-infrared spectroscopy and venous jugular bulb saturation in children. Intensive Care Med 2005;31:846-50.

5. Weiss M, Dullenkopf A, Kolarova A, Schulz G, Frey B, Baenziger O. Near-infrared spectroscopic cerebral oxygenation reading in neonates and infants is associated with central venous oxygen saturation. Paediatr Anaesth 2005;15:102-9.

6. Yoshitani K, Kawaguchi M, Tatsumi K, Kitaguchi K, Furuya H. A comparison of the INVOS 4100 and the NIRO 300 near-infrared spectrophotometers. Anesth Analg 2002;94:586-90.

7. Greisen G. Is near-infrared spectroscopy living up to its promises? Semin Fetal Neonatal Med 2006;11:498-502.

8. Petrova A, Mehta R. Near-infrared spectroscopy in the detection of regional tissue oxygenation during hypoxic events in preterm infants undergoing critical care. Pediatr Crit Care Med 2006;7:449-54.

9. Toet MC, Lemmers PM. Brain monitoring in neonates. Early Hum Dev 2009;85:77-84. 
10. Lemmers PM, Toet $M$, van Schelven LJ, van Bel F. Cerebral oxygenation and cerebral oxygen extraction in the preterm infant: the impact of respiratory distress syndrome. Exp Brain Res 2006;173: 458-67.

11. Menke J, Voss U, Möller G, Jorch G. Reproducibility of cerebral near infrared spectroscopy in neonates. Biol Neonate 2003;83:6-11.

12. Sorensen LC, Greisen G. Precision of measurement of cerebral tissue oxygenation index using near-infrared spectroscopy in preterm neonates. J Biomed Opt 2006;11:054005.

13. Lemmers PM, Toet MC, van Bel F. Impact of patent ductus arteriosus and subsequent therapy with indomethacin on cerebral oxygenation in preterm infants. Pediatrics 2008;121:142-7.

14. Lemmers PM, Molenschot MC, Evens J, Toet MC, van Bel F. Is cerebral oxygen supply compromised in preterm infants undergoing surgical closure for patent ductus arteriosus? Arch Dis Child Fetal Neonatal Ed 2010;95:F429-34.

15. Toet MC, Lemmers PM, van Schelven LJ, van Bel F. Cerebral oxygenation and electrical activity after birth asphyxia: their relation to outcome. Pediatrics 2006;117:333-9.

16. Toet MC, Flinterman A, Laar Iv, et al. Cerebral oxygen saturation and electrical brain activity before, during, and up to 36 hours after arterial switch procedure in neonates without pre-existing brain damage: its relationship to neurodevelopmental outcome. Exp Brain Res 2005;165:343-50.

17. Brady K, Joshi B, Zweifel C, et al. Real-time continuous monitoring of cerebral blood flow autoregulation using near-infrared spectroscopy in patients undergoing cardiopulmonary bypass. Stroke 2010;41: 1951-6.

18. Grubhofer G, Tonninger W, Keznickl P, et al. A comparison of the monitors INVOS 3100 and NIRO 500 in detecting changes in cerebral oxygenation. Acta Anaesthesiol Scand 1999;43:470-5.

19. Cho H, Nemoto EM, Sanders M, Fernandez K, Yonas H. Comparison of two commercially available near-infrared spectroscopy instruments for cerebral oximetry. Technical note. J Neurosurg 2000;93:351-4.

20. Wijbenga RG, Lemmers PM, van Bel F. Cerebral oxygenation during the first days of life in preterm and term neonates: differences between different brain regions. Pediatr Res 2011;70:389-94.

21. Hou X, Ding H, Teng Y, et al. Research on the relationship between brain anoxia at different regional oxygen saturations and brain damage using near-infrared spectroscopy. Physiol Meas 2007;28:1251-65.
22. Dent CL, Spaeth JP, Jones BV, et al. Brain magnetic resonance imaging abnormalities after the Norwood procedure using regional cerebral perfusion. J Thorac Cardiovasc Surg 2005;130:1523-30.

23. Kurth CD, McCann JC, Wu J, Miles L, Loepke AW. Cerebral oxygen saturation-time threshold for hypoxic-ischemic injury in piglets. Anesth Analg 2009;108:1268-77.

24. Gerstner B, DeSilva TM, Genz K, et al. Hyperoxia causes maturation-dependent cell death in the developing white matter. J Neurosci 2008;28:1236-45.

25. McNeill S, Gatenby JC, McElroy S, Engelhardt B. Normal cerebral, renal and abdominal regional oxygen saturations using near-infrared spectroscopy in preterm infants. J Perinatol 2011;31:51-7.

26. Roche-Labarbe N, Fenoglio A, Aggarwal A, et al. Near-infrared spectroscopy assessment of cerebral oxygen metabolism in the developing premature brain. J Cereb Blood Flow Metab 2012;32:481-8.

27. Tina LG, Frigiola A, Abella R, et al. Near Infrared Spectroscopy in healthy preterm and term newborns: correlation with gestational age and standard monitoring parameters. Curr Neurovasc Res 2009;6:148-54.

28. Sorensen LC, Greisen G. The brains of very preterm newborns in clinically stable condition may be hyperoxygenated. Pediatrics 2009;124:e958-63.

29. Austin T, Gibson AP, Branco G, et al. Three dimensional optical imaging of blood volume and oxygenation in the neonatal brain. Neuroimage 2006;31:1426-33.

30. Metz AJ, Biallas M, Jenny C, Muehlemann T, Wolf M. The effect of basic assumptions on the tissue oxygen saturation value of near infrared spectroscopy. Adv Exp Med Biol 2013;765:169-75.

31. Hongo K, Kobayashi S, Okudera H, Hokama M, Nakagawa F. Noninvasive cerebral optical spectroscopy: depth-resolved measurements of cerebral haemodynamics using indocyanine green. Neurol Res 1995;17:89-93.

32. Cui W, Wang N, Chance B. Study of photon migration depths with timeresolved spectroscopy. Opt Lett 1991;16:1632-4.

33. Bernal NP, Hoffman GM, Ghanayem NS, Arca MJ. Cerebral and somatic near-infrared spectroscopy in normal newborns. J Pediatr Surg 2010;45:1306-10.

34. Lemmers PM, van Bel F. Left-to-right differences of regional cerebral oxygen saturation and oxygen extraction in preterm infants during the first days of life. Pediatr Res 2009;65:226-30.

35. Bland JM, Altman DG. Statistical methods for assessing agreement between two methods of clinical measurement. Lancet 1986;1:307-10. 